\title{
Shiftwork: A record study approach
}

\author{
MICHAEL J. COLLIGAN, MICHAEL J. SMITH, and JOSEPH J. HURRELL, JR. \\ National Institute for Occupational Safety and Health, Cincannati, Ohio 45226 \\ and \\ DONALD L. TASTO \\ Tasto Associates, Palo Alto, California 94305
}

\begin{abstract}
The use of employer records to assess shiftwork effects is discussed. Methods for gaining access to records are covered, along with some of the problems involved in evaluating the data. Five general sources of data are described.
\end{abstract}

The use of employer records to assess the health and safety impact of shiftwork has been a popular strategy in previous research efforts (e.g., Nicholson, Jackson, \& Howes, 1978; Pocock, Sergean, \& Taylor, 1972; Walker \& De la Mare, 1971). Aside from the obvious advantage of eliminating the investigator's dependency on live and cooperating subjects for the generation of data, this approach has considerable appeal for a number of other reasons.

Industrial accidents and illnesses are low-probability events, occurring relatively infrequently under normal conditions. Assuming that one does not wish to increase their occurrence through the manipulation of some suspected causative variable, the interested investigator must rely on a field-observation approach. Depending on the size of the work force, a prospective study could require months, or even years of observation in order to produce a behavioral sample of sufficient size to allow for statistical analysis. Furthermore, as one extends the observation period, one increases the likelihood that extraneous events (e.g., strikes, layoffs, normal accretion, etc.) may occur and disrupt the continuity of the study design.

A retrospective approach, on the other hand, offers the security of hindsight. The investigator can control how far back in time he reaches in order to obtain an adequate sample of the behavior under study. Accident and illness rates may be examined over the previous 1-year, 3-year, or 5-year period, depending on the needs of the investigator. Furthermore, the researcher can indirectly control the impact of extraneous factors on his data set by selecting for observation only those time periods that were relatively stable (e.g., strike-free) and representative of normal plant operations. Given the vicissitudinous nature of field research, the retrospective study allows the researcher a well defined historical framework within which to interpret his data.

A second incentive for using a retrospective archival study to assess the health and safety consequences of shiftwork is the fact that the variables of interest (e.g., sickness absence, accidents, etc.) are fairly discrete events that are easily recognized and recorded. Furthermore, all industries have established a system for monitoring worker health and well-being, and although the thoroughness and sophistication of these records may vary from plant to plant, they are usually accessible and can be a rich source of data.

\section{SOURCES OF DATA}

For the investigator concerned with assessing the health and safety of a circumscribed work force, five general sources of information are available from plant archives.

\section{Personnel Records}

These records are typically located in the personnel department and contain sociodemographic information about the individual employees comprising the work force. Age, sex, marital status, job classification, job tenure, and possible preemployment history are available from these records. These variables are of concern to the health researcher in that they may moderate the relationship between the predictor variable (e.g., shift schedule) and outcome variable (e.g., sickness absence). This is especially problematic in shiftwork studies, in that shift assignment is usually determined by seniority, and consequently, it covaries with age and experience. In order to obtain a clearer picture of the shiftworkhealth relationship, these con taminating variables must be controlled through either the sampling plan or the statistical design.

Somewhat surprisingly, individual personnel records do not typically contain any information on employee shift assignment. In those plants that pay a shift differential, an individual's shift assignment can be determined from payroll schedules. An alternate strategy is to obtain shift rosters; when not available, direct verification of shift assignment from the individual supervisors may be necessary. 


\section{Insurance/Lost-Time Claims}

On an a priori basis, this would appear to be a rich data source. Injuries and illnesses of sufficient severity to require medical attention are likely to be described in detail on individual insurance claim forms. Unfortunately, it has been our experience that these records are essentially inaccessible, and any researcher who depends upon this source for collecting data is likely to be disappointed. Private insurance carriers are understandably reluctant to open their records to outside sources, and even if one were able to follow the bureaucratic and legalistic maze necessary to gain permission to access individual claims, the time, expense, and frustration involved would be prohibitive. The company, of course, has legal responsibilities to both the insurance carrier and the individual claimant, and it is therefore similarly reluctant to make its insurance transactions open to inspection. This is likely to be the case even if the investigator is successful in securing permission from the individual claimants to access their insurance records. In short, although insurance and compensation claims appear to be a rich source of data, these records are essentially inaccessible.

\section{Reported Sickness Absence}

An indirect gross estimate of worker health can be gained from an examination of worker absenteeism records due to sickness. This information can usually be found on personnel records or employee health records if the company maintains a separate system of health archives. In addition to the dates of absence, most companies record reasons for absence (e.g., cold, virus, inflamed throat, etc.) as reported by the employee, or, in the case of "prolonged" illness (defined by most companies as involving 3 or more continuous days of absence), an examination and certification of illness by a physician may be required.

Unlike insurance claims and compensation vouchers, these records are maintained at the plant level and are relatively easy to access. By grouping the reasons for sickness absence into standardized classes (e.g., ICDA codes), the investigator can examine not only the frequency of sickness, but also the incidence of specific health problems as a function of shift schedule or any other variable of interest.

\section{Company Clinic/Dispensary Records}

A number of plants have "on-site" health facilities for routine health maintenance and emergency care. The quality and range of services provided by such dispensaries vary considerably from plant to plant. Depending on the size and sophistication of the organization, the plant clinic may involve a staff of medical specialists equipped with the facilities of a small hospital, or it may involve a shop foreman or union steward who has access to a supply of aspirin and antiseptics. Unfortunately, most "health clinics" fall under the latter category, and the quality of available records is likely to reflect this fact. In our own research, for example, we examined the health records of approximately 1,200 nurses in 12 hospital sites (Tasto \& Colligan, Note 1) and found that none of these locales required annual physicals. Furthermore, in a number of cases, the "clinic" consisted of a cabinet of nonprescription medications and a $\log$ for recording the nature of the symptoms and the medication administered. Individual employees who experienced health problems on the job were expected to find their way to the medicine cabinet and fend for themselves. About the best that can be expected of plant clinic records, therefore, is that they provide information regarding the frequency of individual employee clinic visits, the reasons for the visits, and medication usage.

\section{Accident Reports}

Since the establishment of the Occupational Safety and Health Act of 1970, employers of more than 10 people have been required to maintain daily logs of accident and injury occurrences, as well as illness onse ts due to environmental factors associated with employment (e.g., contact dermatitis, silicosis, lead poisoning, etc.). In addition to the employee's name and type of illness or injury, the standard reporting form (OSHA No. 200) requests information regarding the individual's job title and description, number of work days lost, and any resulting restrictions in work activities.

\section{ACCESSING THE DATA}

The majority of time and effort spent in conducting a record study is typically spent in the planning phase. Gaining access to company records can be a wearisome process requiring considerable diplomatic skills and patience. As a rule of thumb, it is advisable to initiate contact with the individual in the organization having the most authority with respect to personnel (e.g., personnel manager, personal director, etc.). In addition to being knowledgeable about the location and nature of data sources within the organization, this individual's cooperation will undoubtedly be necessary to access the relevant records. Securing access to the company records is obviously a critical step in the investigative process and, as such, should receive as much attention and thought as the study design itself.

In general, the investigator should be prepared to discuss four areas of concern at his initial contact. There are the study rationale, the legal ramifications, the mechanics of the study, and the company gain. (1) The study rationale: This might involve a brief background statement describing the state of the art and a justification for the proposed research. (2) The legal ramifications: This is a complex issue and may involve repeated negotiations. Of immediate concern are issues relating to protecting individual confidentiality 
and anonymity. If the investigator intends to review the records himself, it may be necessary to obtain informed consent from each individual whose record is examined. If a company representative accesses the files and transcribes the information for the researcher, individual consent may not be necessary if identifiers are stripped from the records. At any rate, the researcher should be aware of these issues and be flexible in considering alternate approaches. (3) The mechanics of the study: The researcher should have a tentative sampling plan that provides an estimate of how long the study will run and what impact participation will have on employee productivity and organizational functioning. Understandably, the company's concern is that the research be completed as quickly and unobtrusively as possible. (4) The company gain: The company is not in business to generate data for behavioral science field researchers. Before an organization will consent to participate in a study, it must be convinced that the benefits resulting from company involvement will outweigh the inconveniences. Of concern here are issues about the use and availability of the data and its potential value to the company. Publication plans, guarantees of company anonymity in public reports, and manuscript review agreements between the researcher and the company are issues that might arise along these lines. The investigator may wish to consider preparing private reports or doing special analyses for internal company use as an incentive to elicit cooperation. These would involve examining hypotheses or data that are of no interest to the investigator but that may be of value to the participating parties. In this respect, the researcher should be prepared to barter goods and services in order to reach an amiable exchange among the study members.

Whether the researcher approaches the company directly or through a labor union representative in initiating these contacts, it is recommended that all three parties (i.e., researcher, management, and labor) be completely informed and in agreement about all basic issues related to the research. This may require considerable time and effort in the planning stages, but can prevent some disastrous consequences in the long run.

\section{EVALUATING THE DATA}

The advantages and disadvantages of archival research relative to other study designs are well known (e.g., Aronson \& Carlsmith, 1968; Webb, Campbell, Schwartz, $\&$ Sechrest, 1966). Nevertheless, a review of the shiftwork literature involving record assessment of worker safety and health highlights a number of issues that merit attention.

The first has to do with the fact that the reported incidence of accidents and illness in industry is not the same as the actual incidence of these events. Workers or their supervisors may choose not to report minor injuries in order to avoid the required paper work, or to escape company sanction, or for any of a variety of reasons. Conversely, workers may report illnesses as a means of justifying an occasional "free" day; school children are not the only ones who play hookey. Technically, therefore, the shiftwork researcher who uses a record study approach is examining the effects of shift schedule on the reporting of accidents and injuries, not their actual occurrence. This has obvious implications for any inferences drawn regarding the impact of shift schedule on worker safety and health. Differences across shifts in the reported incidence of accidents and illnesses may be more a function of differential reporting practices than actual heal th status. Company reporting facilities may not be equally accessible to all shifts (i.e., the clinic may be closed at night), and the careless investigator could be drawn to some inappropriate conclusions. Care should be taken to ascertain the comparability of the various shifts in terms of accessibility to the recording station.

A related issue is the fact that most companies presently allow their employees a given number of excused sick days per year. For many workers, this is viewed as added vacation time should they not have to use it for actual sickness. Employees may therefore take the maximum number of sick days each year whether they need them or not. This "ceiling effect" may cut down on the observed variance across shifts and mask any true differences in illness rates due to shift schedule. The astute researcher may therefore wish to use multiple measures (sickness absence, clinic visits, medication usage, etc.) in order to obtain as clear a picture as possible of the health status of the individual workers.

Finally, shiftwork researchers must be aware of the crossover problem (Mott, Mann, McLoughlin, \& Warwick, 1965; Tasto \& Colligan, Note 1). It is unusual for a worker to stay on one shift for his entire working career. It may be the case that a health problem that an individual is currently experiencing is the result, not of his present shift, but of a previous shift regime. Wherever possible, the researcher should attempt to obtain shift history information on the individuals in his sample to allow for an examination of migration patterns and their relation to health and safety status.

Despite these and other limitations, a record study approach is a viable means of evaluating the impact of shift schedule on worker safety and health. It should be recognized that shiftwork is an extremely controversial issue, around which has evolved a complex web of personnel policies, production practices, and industrial relations. Any investigation that elicits the active participation of subjects in the data collection phase is susceptible to possible measurement con tamination from subject reactivity (Aronson \& Carlsmith, 1968; Hendrick \& Jones, 1972; Orne, 1962; Silverman, Note 2). Whether intentional or not, the greater the 
vested interest of the participant in the outcome of a study, the greater the chance for some type of respondent bias.

A record study obviously escapes the more blatant forms of systematic response bias in that the subjects (and possibly the experimenter) are incapable of anticipating the eventual hypotheses to be tested at the time the behaviors are recorded. The individual workers are not reporting illnesses or injuries to confirm or disconfirm presumed hypotheses about the nature of shiftwork, but rather, as a required part of their daily work routines. Given the controversial nature of this issue, this in itself is a strong argument for an archival approach

\section{REFERENCE NOTES}

1. Tasto, D. L., \& Colligan, M. J. Health consequences of shift work. DHEW (NIOSH) Publication No. 78-154. Washington, D.C: U.S. Government Printing Office, 1978.

2. Silverman, I. Motives underlying the behavior of the subject in the psychological experiment. Paper presented at annual meeting of the American Psychological Association, Chicago, September 1965.

\section{REFERENCES}

Aronson, E., \& Carlsmith, J. M. Experimentation in social psychology. In G. Lindzey \& E. Aronson (Eds.), The handbook of social psychology (Vol. 2). Reading, Mass: Addison-Wesley, 1968.

HENDRick, C., \& Jones, R. A. The nature and theory of research in social psychology. New York: Academic Press, 1972.

Mott, P. E., Mann, F. C., McLoughin, Q., \& Warwick, D. P. Shiftwork: The social, psychological, and physical consequences. Ann Arbor: University of Michigan Press, 1965.

Nicholson, N., Jackson, P., \& Howes, G. Shiftwork and absence: An analysis of temporal trends. Journal of Occupational Psychology, 1978, 51, 127-137.

ORNE, M. On the social psychology of the psychological experiment. American Psychologist, 1962, 17, 776-783.

Pocock, S. J., Sergean, R., \& TAYLoR, P. J. Absence of continuous three shift workers: A comparison of traditional and rapidly rotating systems. Occupational Psychology, 1972, 46, $7-13$.

WAIKeR, J., \& De la MARE, G. Absence from work in relation to the length and distribution of shift hours. British Journal of Industrial Medicine, 1971, 28, 36-44.

Webi, E. J., Campbell, D. T., Schwartz, D., \& Sechrest, L. Unobtrusive measures: Nonreactive research in the social sciences. Chicago: Rand-McNally, 1966. 